Brit. Heart f., 1967, 29, 30.

\title{
Heart Failure with Brain Damage in the Newborn
}

\author{
O. P. GRAY AND R. PROSSER \\ From the Department of Child Health, Welsh National School of Medicine, Cardiff
}

Sudden brain injury in adults can cause pulmonary œdema which may be due to heart failure. In the newborn, heart failure can occur with cerebral damage and lead to diagnostic difficulties, as the cardiac signs are identical with those of congenital heart disease. It is important to be aware that an anatomically normal heart can fail from this cause in the neonatal period, so that correct treatment and parent counselling can be undertaken. Any newborn infant who develops heart failure should have a careful evaluation of his central nervous system. We report three cases in which cardiac failure occurred with cerebral birth injury in babies whose hearts were anatomically normal.

\section{CASE REPORTS}

Case 1. This baby girl, weighing $3780 \mathrm{~g}$. was born at term by a normal spontaneous vertex delivery. The mother developed gross oedema at 36 weeks. At birth the infant was covered in and stained with meconium, and the Apgar score was 2. The face was Cushingoid, and covered with petechiae. Shortly after birth there was insuction, central cyanosis, rapid respirations (64 a minute), and an expiratory grunt. The air entry was normal but there were fine bilateral crepitations. No murmur was audible. The anterior fontanelle tension was normal. The baby was hypotonic and lay in the frog position, but sucked and cried satisfactorily.

At the age of 12 hours there was marked right and left parasternal pulsation with a pulse rate of 112 a minute. There was no murmur, but there was wide splitting of the pulmonary second sound and the liver edge was $4 \mathrm{~cm}$. below the costal margin. The heart was greatly enlarged, both clinically and radiologically. A diagnosis of cardiac failure was made on the basis of the large heart, hepatomegaly, rapid respirations, central cyanosis, and bilateral crepitations. Digitalis was given.

It was clear that the baby had cerebral damage, as she developed twitchings of the left arm, shoulder, and leg, in addition to the hypotonia, irritability, and abnormal posture. The blood glucose was $40 \mathrm{mg} .100 \mathrm{ml}$. Shortly afterwards, the infant had both major convulsions and myoclonic jerkings treated with paraldehyde

Received November 26, 1965. and sodium phenytoin. The radiograph (Fig. 1) taken at this time demonstrates the enlarged heart.

During the second day the anterior fontanelle tension was increased, the child lay with eyes wide open, and the tone was variable. There were several episodes of. twitching. The insuction, bilateral crepitations, right ventricular pulsation, and hepatomegaly remained. During the next four days the abnormal cardiac and cerebral signs slowly disappeared. When discharged at the age of 20 days the baby still had a moon face, with strikingly sunken eyes. The radiograph (Fig. 2) showed that the heart size was reduced. When last seen at 8 months the infant was thriving, but was hypotonic and stages of development were delayed. The heart was normal.

Case 2. This infant was born at term by an uncomplicated spontaneous vertex delivery, weighing 3094 g., and the Apgar score was 8. At 10 hours she was pale and dusky. The respiratory rate was 60 a minute, and there was slight insuction. There was a grade 2-3 systolic murmur, the femoral pulses were palpable, and the blood pressure was $75 \mathrm{~mm}$. $\mathrm{Hg}$, mean systolic. The baby was given antibiotics and nursed in an incubator. At 16 hours the alae nasi were working and the breathing was laboured. There was a visible and palpable cardiac pulsation. The systolic murmur remained unchanged. The electrocardiogram showed a large right ventricle and right atrium. The radiograph confirmed the large heart.

At 36 hours the respiratory rate was 72 a minute, the insuction was more marked, and the liver edge was palpable $5.5 \mathrm{~cm}$. below the costal margin. The signs in the heart were unchanged.

The child lay in the frog position, staring, and stuporose. The sutures were separated, and the Moro reflex, sucking, and grasp reflexes were absent. The head circumference had risen from 32.5 to $35 \mathrm{~cm}$. It was thought that the child had both heart failure due to the congenital heart disease and cerebral damage. She was given digitalis and diuretics.

By the fourth day the heart failure had improved considerably, and the insuction, visible pulsation, and murmur had disappeared. The liver had returned to normal size. The cerebral signs persisted, and the 30 


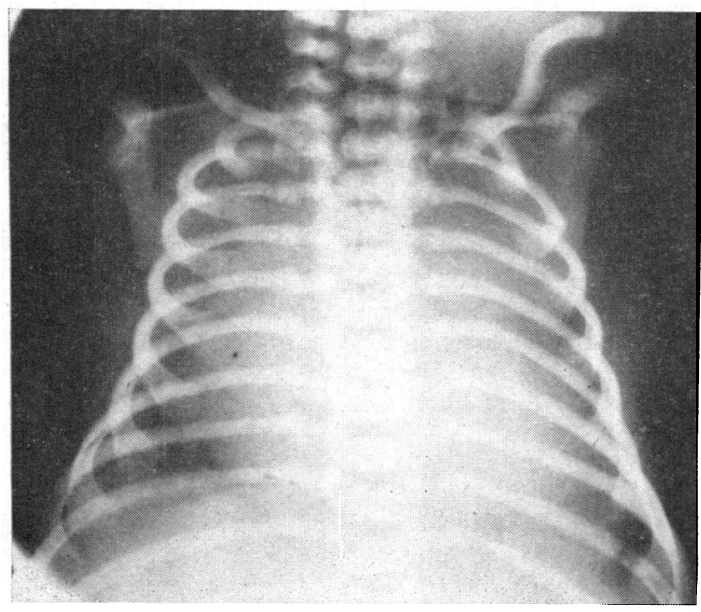

FIG. 1.-Radiograph of Case 1 taken at 12 hours, showing enormous dilatation of heart.

circumference was now $35.7 \mathrm{~cm}$. The anterior fontanelle, which had been tense, became normal on the seventh day, as did the baby's reactivity and reflexes. The systolic murmur was still present and lasted until the age of 3 months when it disappeared, and the heart was considered to be normal.

Case 3. This infant was the younger sister of Case 2. She was born by breech delivery with forceps to the after-coming head, the birthweight being $3760 \mathrm{~g}$. The Apgar score was 8. Regular breathing with a good pulse rate was established immediately, but the child had some cyanosis. She was dysmature. At the age of 6 hours there was marked central cyanosis and irritability, with a high-pitched cry. She lay in the frog position. The respiratory rate had risen to 100 a minute, and insuction was evident. The air entry was equal and there were no adventitious sounds, but there was a grade 3 systolic murmur heard down on the left side of the sternum, maximal at the lower end. The pulmonary second sound was split and accentuated. The radial and femoral pulses were palpated with difficulty and the blood pressures in the right arm and leg were 60 and $75 \mathrm{~mm} . \mathrm{Hg}$, respectively. The cardiovascular signs were identical with those of the sib, and again congenital heart disease was suspected. The liver edge was palpable $2 \mathrm{~cm}$. below the costal margin. A radiograph of the chest showed the presence of an enormous heart and the dilatation was largely right-sided (Fig. 3). This was confirmed by an electrocardiogram.

At 10 hours the murmur was louder. The relevant biochemical findings at this time were $p \mathrm{H} 7.04, \mathrm{PcO}_{2}$ $63 \mathrm{~mm}$. Hg, base deficit $17 \mathrm{mEq} / \mathrm{l}$., true glucose 60 $\mathrm{mg} . / 100 \mathrm{ml}$. The infant was given digitalis and nursed in an incubator. At 24 hours her condition was worse: there were signs of a forceful right ventricle and abnormal cerebral signs. She lay in the frog position with fists tightly clenched, and diminished reflexes. The true blood glucose had now dropped to $8 \mathrm{mg}$. $/ 100 \mathrm{ml}$. and the $p \mathrm{H}$ was $7 \cdot 24, \mathrm{PcO}_{2} 64 \mathrm{~mm}$. $\mathrm{Hg}$.

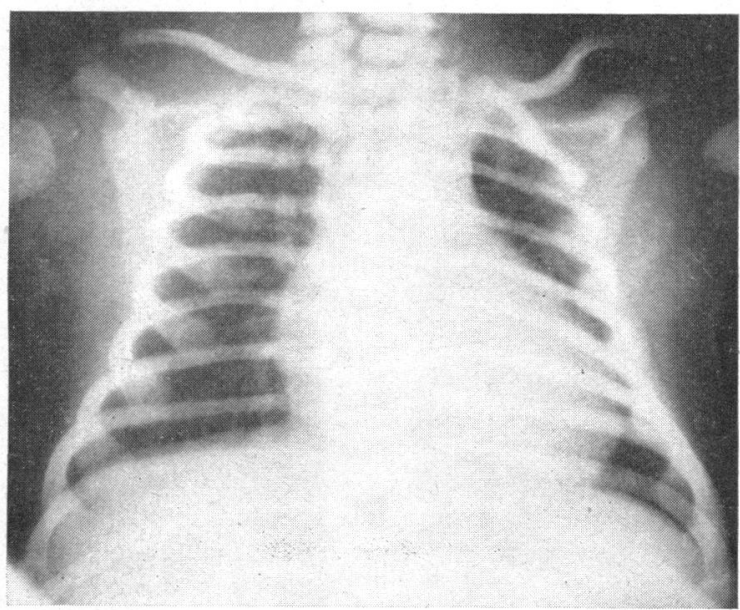

FIG. 2.-Radiograph of Case 1 at 20 days, showing reduction in heart size.

At 36 hours the child's condition deteriorated further, with bile-stained vomiting. The liver was large and firm, and the edge was palpable $5 \mathrm{~cm}$. below the costal margin. The anterior fontanelle was tense. The patient remained hypotonic and the reflexes were absent. The attempt to correct the hypoglycæmia by intragastric feeding was replaced by calf vein transfusion.

The child died at the age of 45 hours, and at necropsy there was marked cerebral œdema, subarachnoid hæmorrhage, and coning. The heart was large and the right atrium was enormous, but no anatomical abnormality was detected. The liver was enlarged, and the kidneys showed enlargement and congestion compatible with heart failure.

\section{Discussion}

These three children had the signs of heart failure, namely raised respiratory rate, insuction,

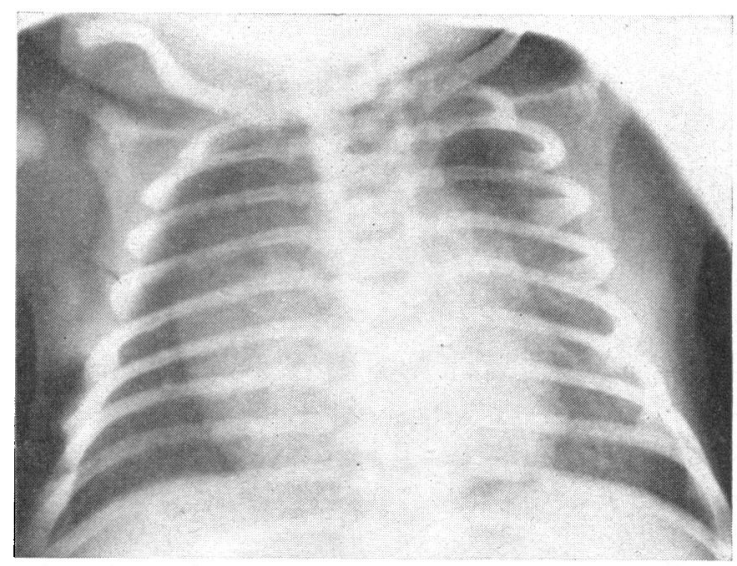

FIG. 3.-Radiograph of Case 3 at 6 hours, showing a big heartlargely right-sided dilatation. 
hepatomegaly, cardiomegaly, and cyanosis, arising within a few hours of birth. One of the children died of heart failure but had an anatomically normal heart, and in the other two the heart subsequently was normal. The cerebral signs were also present from the early hours of life but were overshadowed by the heart failure. The abnormal cerebral signs were first found from the age of 6 to 36 hours. Cerebral damage was confirmed in one baby at necropsy, whereas in the other two, one seems to have made a full recovery and at the age of 11 months was normal, but the other child has features suggesting permanent brain damage. There are several possible relationships between cerebral damage and the functional heart failure. The first possibility is that the heart failure may have caused cerebral œdema. This is unlikely for several reasons. The cerebral signs developed before there were signs of marked heart failure, and certainly before dependent œdema had appeared. Infants dying in the neonatal period from heart failure due to congenital heart disease show little cerebral œdema. As these infants were nursed in a semiupright position any odema would be more likely to be first noticed in the most dependent areas-the legs and feet. Oedema was not a marked feature in these cases.

Burnard and James (1963) showed that asphyxia can increase the size of the heart. The dilatation was most marked in babies who had severe asphyxia, especially if in addition they had a large placental transfusion. They believe that the reason for the dilatation of the heart is myocardial anoxia. They also reported (1961) 33 babies who were ill in the neonatal period after undue birth asphyxia: 19 of them died. They considered that heart failure was the cause of dyspnœa in these babies, and concluded that there was a disturbance in the hæmodynamics requiring further investigation. Dawes, Mott, and Shelley (1959), Dawes et al. (1960), Shelley (1961), and Mott (1961) have shown that in the newborn animal subjected to intrapartum anoxia the low glycogen content of the cardiac muscle is rapidly depleted. While there was some evidence of asphyxia in Case 1-namely fotal distress and an Apgar score of 2-the infant quickly recovered spontaneously, and with Case 2 there was no clinical evidence of asphyxia. Certainly in no child was there sufficient asphyxia to cause the child to be profoundly shocked at the moment of, or shortly after, birth.

The more likely possibility is that the cerebral damage was largely responsible for the functional heart failure. Cameron and $\mathrm{De}$ (1949) found experimentally an association between intracranial lesions, pulmonary œdema, and changes in the cardiovascular system. Intracisternal injection of fibrin in the animal caused pulmonary œdema which only happened when the vagi were intact. It was thought to be due to a mechanical disturbance in pulmonary blood flow as carotid artery pressure rose initially and fell to subnormal levels, while the right atrial pressure rose and remained high until death. Similar pressure changes were found also when the intracranial pressures were raised by other means, or when fibrin was injected with the vagi divided, but without the occurrence of associated pulmonary œdema. As the complicated changes in the circulation in the early moments after birth are partially mediated through nervous mechanisms, it is reasonable to suppose that injury to the nervous system may interfere with the co-ordinated cardiovascular changes.

Pulmonary œedema has been recorded with a variety of intracranial lesions in adults. Paine, Smith, and Howard (1952) suggested that this was entirely explicable on the basis of heart failure. Yet a further association between cerebral accidents and cardiac lesions is the finding of grossly abnormal electrocardiograms which simulate severe ischæmic heart disease in patients with cerebrovascular accidents (Harrison and Gibb, 1964; Srivastava and Robson, 1964; Menon, 1964). The hearts of these patients were often shown to be normal.

Paine et al. (1952) give clinical and experimental evidence suggesting that every heart has a failure threshold-a maximum of work which cannot be exceeded. In the normal heart this initial work level is high and only rarely exceeded, but in a damaged heart the failure level is lower. In the perinatal period, the heart is stressed by the various adaptations to the adult type circulation. The failure threshold may be passed when additional strains are imposed through neural mechanisms. The mode of action of these nervous mechanisms is obscure, but the possibility that they are largely autonomic is suggested by the finding of generalized pallor, occasional temporary hypertension, and disturbances in heart rhythms.

\section{SUMMARY}

The case histories of three babies are presented to illustrate the failure of an anatomically normal heart in the presence of cerebral damage. The possible mechanisms are discussed. It is easy to make a mistaken diagnosis of congenital heart disease in this situation.

We are indebted to Professors A. G. Watkins and Jethro Gough for their help to Dr. K. M. Laurence for 
the necropsy report, to the Department of Medical Illustration for the X-ray pictures, and to Miss $\mathrm{A}$. Mayled.

\section{REFERENCES}

Burnard, E. D., and James, L. S. (1961). Failure of the heart after undue asphyxia at birth. Pediatrics, 28, 545 . and - (1963). Atrial pressures and cardiac size in the newborn infant. F. Pediat., 62, 815.

Cameron, G. R., and De, S. N. (1949). Experimental pulmonary œdema of nervous origin. f. Path. Bact., 61, 375.

Dawes, G. S., Jacobson, H. N., Mott, J. C., and Shelley, H. J. (1960). Some observations on fotal and new-born rhesus monkeys. F. Physiol. (Lond.), 152, 271.

-, Mott, J. C., and Shelley, H. J. (1959). The importance of cardiac glycogen for the maintenance of life in fœtal lambs and new-born animals during anoxia. F. Physiol (Lond.), 146, 516.

Harrison, M. T., and Gibb, B. H. (1964). Electrocardiographic changes associated with a cerebrovascular accident. Lancet, 2, 429.

Menon, I. (1964). Electrocardiographic changes simulating myocardial infarction in cerebrovascular accident. Lancet, 2, 433.

Mott, Joan C. (1961). The ability of young mammals to withstand total oxygen lack. Brit. med. Bull., 17, 144.

Paine, R., Smith, J. R., and Howard, F. A. (1952). Pulmonary œdema in patients dying with disease of the central nervous system. F. Amer. med. Ass., 149, 643.

Shelley, H. J. (1961). Glycogen reserves and their changes at birth in anoxia. Brit. med. Bull., 17, 137.

Srivastava, S. C., and Robson, A. O. (1964). Electrocardiographic abnormalities associated with subarachnoid hæmorrhage. Lancet, 2, 431. 